\title{
CrimRxiv
}

\section{Enhancing relationships between criminology and cybersecurity}

Benoit Dupont, Chad Whelan

Published on: Mar 27, 2021

License: Creative Commons Attribution 4.0 International License (CC-BY 4.0). 
